\title{
Apuntes sobre la conservación y restauración del patrimonio en México
}

Gabriela Lee Alardin *

\section{Resumen}

El patrimonio cultural de México, de una gran riqueza cuantitativa y cualitativa, abarca desde los restos materiales de las civilizaciones prehispánicas hasta las manifestaciones culturales contemporáneas. La conservación y restauración del patrimonio se rige por distintos criterios, de acuerdo a su clasificación y a los lineamientos aceptados a nivel internacional en la materia.

En esta reseña se presentan las definiciones de lo que constituye el patrimonio arqueológico, histórico y artístico de México, la legislación vigente para su protección, y las instituciones encargadas de su protección y conservación. Se expone también un panorama de la historia de la conservación y restauración del patrimonio.

Palabras-clave: México. Preservación. Patrimonio.

\section{Notes on the conservation and restoration of Mexico's cultural heritage}

\begin{abstract}
México's cultural heritage, of a great variety and number, ranges from the material remnants of pre-hispanic civilizations to contemporary cultural manifestations. The conservation and restoration of this rich ensemble is oriented by rigid criteria, according to its classification and the guidelines issued from international organs.

This paper presents the definitions of what is considered to be the country's archeological, historic and artistic heritage, the legislation currently effective for its protection, and the institutions in charge of its preservation. A brief outlook of the history of conservation and restoration in Mexico is also appreciated.
\end{abstract}

Key-words: Mexico. Preservation. Heritage. 


\section{Introducción}

El patrimonio cultural de México, de una gran riqueza cuantitativa y cualitativa, abarca desde los restos materiales de las civilizaciones prehispánicas hasta las manifestaciones culturales contemporáneas. La conservación y restauración del patrimonio se rige por distintos criterios, de acuerdo a su clasificación y a los lineamientos aceptados a nivel internacional en la materia.

En esta reseña se presentan las definiciones de lo que constituye el patrimonio arqueológico, histórico y artístico de México, la legislación vigente para su protección, y las instituciones encargadas de su protección y conservación. Se expone también un panorama de la historia de la conservación y restauración del patrimonio.

\section{La clasificación del patrimonio}

Las etapas del desarrollo histórico del país se relacionan con los patrones de ocupación del territorio y se reflejan en la producción y características del patrimonio monumental arquitectónico y urbano. La clasificación del patrimonio se establece de acuerdo a criterios relacionados con acontecimientos históricos, y por lo tanto, las categorías de estudio no siempre coinciden claramente con los cambios de métodos constructivos, de tipologías o de tendencias compositivas.

La Ley Federal sobre Monumentos y Zonas Arqueológicos, Artísticos e Históricos establece las siguientes definiciones:

Son monumentos arqueológicos los bienes muebles e inmuebles, producto de culturas anteriores al establecimiento de la hispánica en el territorio nacional, así como los restos humanos, de la flora y de la fauna, relacionados con esas culturas.

Entran en esta categoría todos los vestigios de las culturas prehispánicas, de fecha anterior a 1521, año de la llegada de Hernán Cortés a América.

Son monumentos históricos los bienes vinculados con la historia de la nación, a partir del establecimiento de la cultura hispánica en el país, en los términos de la declaratoria respectiva o 
por determinación de la ley. Por determinación de esta ley son monumentos históricos (...) los inmuebles construidos en los siglos XVI al XIX, destinados a templo y sus anexos (...); así como a la educación y a la enseñanza, a fines asistenciales o benéficos al servicio y ornato público y al uso de las autoridades civiles y militares.

Corresponde a este apartado el patrimonio del período colonial (1521 a 1810) y del resto del siglo XIX.

Son monumentos artísticos los bienes muebles e inmuebles que revistan valor estético relevante. Para determinar el valor estético relevante de algún bien se atenderá a cualquiera de las siguientes características: representatividad, inserción en determinada corriente estilística, grado de innovación, materiales y técnicas utilizados, y otras análogas. Tratándose de bienes inmuebles, podrá considerarse también su significación en el contexto urbano.

De éste último párrafo se desprende que el patrimonio arquitectónico y urbano edificado a partir de 1900 puede ser considerado como monumento artístico, mas no como monumento histórico.

Las siguientes cifras, proporcionadas por el Instituto Nacional de Antropología e Historia, permiten dimensionar el universo de los bienes patrimoniales en México: existen 33,000 zonas arqueológicas registradas, de las cuales 174 se encuentran abiertas al público, y se estima un total de 110,000 monumentos históricos, de los cuales poco más de 67,000 están catalogados. Además México cuenta con 26 sitios inscritos en la lista del Patrimonio Mundial de la Humanidad, que consisten en zonas naturales, zonas arqueológicas, y conjuntos históricos urbanos y rurales.

\section{La legislación para la conservación del patrimonio}

Las leyes sobre conservación del patrimonio en México se remontan al siglo XIX: el primer proyecto de Ley para la Conservación de Monumentos Arqueológicos data de 1862, y la primera Ley sobre Monumentos Arqueológicos se promulgó en 1897, seguida por la Ley de Bienes Nacionales de 1902. 
Durante el siglo XX se promulgaron las siguientes leyes: Ley sobre Conservación de Monumentos Históricos y Artísticos y Bellezas Naturales de 1914, que especifica que dichos monumentos constituyen un patrimonio de la cultura universal; Ley sobre Conservación de Monumentos, Edificios, Templos y Objetos Históricos o Artísticos de 1916, que antepone el valor artístico de los bienes a su valor histórico; Ley sobre Protección y Conservación de Monumentos Arqueológicos e Históricos, Poblaciones Típicas y Lugares de Belleza Natural de 1934, que establece la diferencia entre bienes arqueológicos prehispánicos y bienes históricos coloniales; Ley del Patrimonio Cultural de 1970, que amplía la protección a los bienes de las culturas populares; y finalmente, la Ley Federal sobre Monumentos y Zonas Arqueológicas, Artísticas e Históricas de 1972, reformada en 1984, que sigue vigente al día de hoy.

En Protección del patrimonio cultural urbano, Salvador Díaz-Berrio apunta como aportaciones importantes de la Ley de 1972,

la consideración global del patrimonio cultural, incluyendo bienes muebles, conjuntos de inmuebles, zonas y áreas culturales; la inclusión de conjuntos de inmuebles en zonas de monumentos históricos o artísticos; la inclusión explícita los bienes culturales del siglo XIX como zonas o monumentos históricos; el establecimiento de un registro público de zonas y monumentos; (...) el otorgamiento de estímulos fiscales; y la posibilidad de proteger espacios abiertos o elementos topográficos, cuyo conjunto revista un valor estético.

Sin embargo, detecta algunas imprecisiones que se refieren a la división arbitraria de bienes históricos o artísticos en función de una fecha (1900), y al hecho de que las zonas de monumentos no gozan del criterio global que aplica al patrimonio cultural en su conjunto. Precisa asimismo que los espacios abiertos o elementos topográficos no sólo poseen un valor estético, sino que deben considerarse como parte integral de las zonas arqueológicas e históricas.

José Becerril, en El derecho del patrimonio histórico-artístico en México, es incluso más crítico al afirmar que, si bien nuestra legislación actual funcionó para mitigar el problema del saqueo de los monumentos arqueológicos, no siempre ha resultado un instrumento 
jurídico eficaz. Explica que la ley se basa en una concepción estática de la protección del patrimonio histórico-artístico, como si éste fuera un "tesoro depositado", y por lo tanto impone restricciones a la propiedad privada, a la ejecución de obras, y a la exportación, reproducción, y exploración de monumentos. Por otro lado, la ley no toma en cuenta la función y la dinámica real a la que se encuentran sujetos dichos bienes, y no prevé una participación adecuada de los diversos grupos sociales en la protección del patrimonio.

Conviene destacar que el carácter arqueológico de un bien tiene prioridad sobre su carácter histórico, y este a su vez sobre el carácter artístico. De esta manera se dirime cualquier duda sobre los criterios que deben prevalecer en cada caso particular.

De acuerdo a la Ley, no es obligatoria la participación de un especialista en intervenciones sobre monumentos históricos y artísticos, pero si lo es en las intervenciones sobre el patrimonio arqueológico.

De la ley de 1972 y su reglamento, aprobado en 1975, se desprenden leyes y disposiciones estatales y municipales, así como el marco jurídico de las instituciones encargadas de la salvaguarda del patrimonio.

\section{Las instituciones a cargo de la protección del patrimonio}

La ley establece que la conservación y restauración del patrimonio de todos los períodos es competencia del gobierno. En primer término, de las instancias federales, es decir del Presidente de la República y de la Secretaría de Educación Pública, bajo el mandato de la cual actúa un órgano desconcentrado, el Consejo Nacional para la Cultura y las Artes (CONACULTA), que a su vez coordina las labores de la Dirección General de Sitios y Monumentos del Patrimonio Cultural, del Instituto Nacional de Antropología e Historia (INAH) y del Instituto Nacional de Bellas Artes (INBA). Adicionalmente, los gobiernos estatales y municipales tienen su propia Dirección de Monumentos y Sitios Patrimoniales. 
La Dirección General de Sitios y Monumentos del Patrimonio Cultural es el órgano del gobierno que se encarga de la integridad de los bienes que conforman el patrimonio cultural de la Nación, es decir los inmuebles federales. EI INAH tiene a su cargo el patrimonio arqueológico e histórico, y se apoya en una estructura de 31 Centros Regionales, mientras que al INBA corresponde la custodia del patrimonio artístico de la nación.

Numerosas universidades, instituciones privadas, asociaciones civiles y profesionales, fundaciones, y fideicomisos, participan activamente en la conservación y restauración del patrimonio. Entre las más relevantes figuran la Universidad Nacional Autónoma de México, la Sociedad Mexicana de Arquitectos y Restauradores, el Colegio de Maestros en Arquitectura, Restauradores de Sitios y Monumentos, la Comisión Nacional de Arte Sacro, y el Fideicomiso del Centro Histórico de la Ciudad de México.

Además operan en México los capítulos locales de organismos internacionales como el Internacional Council of Monuments and Sites (ICOMOS), y el Documentation and Conservation of buildings, sites and neighborhoods of the Modern Movement (DOCOMOMO).

Es necesario mencionar la relación entre la legislación en materia de desarrollo urbano y la conservación del patrimonio. Las disposiciones formuladas en la Ley General de Asentamientos Humanos y en el Programa Nacional de Desarrollo Urbano hacen referencia a la protección de los bienes patrimoniales, pero existen numerosos obstáculos para la aplicación de estos principios en los programas municipales de desarrollo urbano - por ejemplo, la falta de parámetros claros y de personal especializado para que las autoridades locales puedan evaluar la pertinencia de determinadas acciones de construcción, remodelación, o restauración. Además, sobre un mismo inmueble o zona patrimonial aplica la autoridad del gobierno local y de las instituciones del gobierno federal, por lo que los procesos de autorización de licencias pueden llegar a ser sumamente complejos. 


\section{Breve panorama de la conservación y restauración del patrimonio en México}

Se han desarrollado pocos estudios que apunten hacia una historiografía crítica de las restauraciones del patrimonio desarrolladas en México. Aunque está documentada una larga actividad ininterrumpida de acciones de exploración, estudio, documentación, restauración e intervención en los bienes culturales, la gran mayoría de las publicaciones son memorias descriptivas que versan sobre las características estéticas o la evolución histórica de los inmuebles y monumentos, y no ahondan sobre los aspectos teóricos de la conservación y restauración del patrimonio. La revisión de las intervenciones realizadas es una labor pendiente, y de gran trascendencia para poder evaluar las políticas vigentes y en caso necesario replantearlas con miras a lograr programas integrales de conservación del patrimonio.

\section{a) El patrimonio Arqueológico}

El patrimonio arqueológico consiste en esencia en edificios, monumentos u objetos que han perdido su función de habitación o de utilidad práctica; son vestigios de culturas o civilizaciones desparecidas.

Desde fines del siglo XIX, se llevó a cabo un intenso trabajo arqueológico, auspiciado por el Instituto Nacional de Antropología e Historia (INAH) a partir de su fundación en 1939. Las primeras exploraciones sistemáticas y reconstrucciones arqueológicas iniciaron en el siglo XX. Según relata Alejandro Mangino Tazzer, una de las obras más significativas de ese período fue el proyecto de excavaciones del conjunto de la Ciudadela en Teotihuacan, iniciado en 1917 bajo la dirección de Manuel Gamio, Ignacio Marquina y José Reygadas Vértiz. En esta obra se procedió a la remoción de escombros para determinar los volúmenes a ambos lados del eje principal de la pirámide, y se recurrió a la anastilosis, con la dificultad que implicaba el uso de esta técnica en estructuras de mampostería y argamasa. Para reconstruir los elementos faltantes se emplearon materiales de los escombros, y se sustituyeron las losas rotas por otras de dimensiones iguales para apoyar los tableros de acuerdo al proceso constructivo original. 
Ignacio Bernal, en Historia de la arqueología en México, explica que las excavaciones y restauraciones de sitios arqueológicos se han realizado con recursos públicos. En un principio la finalidad de dichas obras no era tanto la investigación arqueológica en si misma, sino la conservación de las ruinas y objetos antiguos como símbolos y explicación del pasado nacional. También fue importante el fomento del turismo basado en la arqueología. Según apuntaba Augusto Molina Montes en 1975, durante décadas se realizó un intenso trabajo arqueológico sin contar con un sustento teórico adecuado, y la reflexión sobre las intervenciones efectuadas era escasa, y tenía como finalidad primordial la reconstrucción de los monumentos arqueológicos.

A partir de 1964, México declaró su adhesión a los principios enunciados en documentos internacionales como la Carta de Venecia y las Normas de Quito. Sin embargo, se siguieron realizando trabajos de restauración en zonas arqueológicas que contravenían dichos principios, como es el caso de las reconstrucciones arquitectónicas en la zona arqueológica de Cholula - donde varios segmentos de la pirámide fueron reconstruidos en concreto - y en el Palacio de las Mariposas en Teotihuacan - donde también se reconstruyeron elementos decorativos como relieves y pinturas murales.

Los trabajos de restauración requieren de una estrecha colaboración entre arquitectos, restauradores y arqueólogos para intervenir en los bienes arqueológicos, en los conjuntos urbanos y en el paisaje característico de cada sitio. Sin embargo, la incorporación de conocimientos de restauración arquitectónica a la formación de los arqueólogos es un fenómeno relativamente reciente, así como la preocupación por integrar criterios aceptados internacionalmente al trabajo de restauración arquitectónica de edificios arqueológicos.

Hoy en día existe un acuerdo entre los profesionistas del ramo sobre la importancia primordial del respeto hacia la sustancia material del monumento como documento de su valor histórico. En las intervenciones en monumentos arqueológicos el valor histórico predomina por encima de cualquier otra consideración, y prevalece la conservación de los restos materiales, descartándose intervenciones invasivas que pudieran destruir las 
huellas del paso del tiempo por los monumentos. Se recomienda que si, durante el proceso de un trabajo arqueológico, se interviene en un monumento, sea obligatoria la conservación, quede vedada la reconstrucción, y los otros aspectos de la restauración sean sometidos a un estudio minucioso. Se sugiere hacer reconstrucciones hipotéticas en maquetas, o en registros digitales que no alteren el monumento mismo, o bien, en los casos en que no exista duda sobre la volumetría original, realizarlas con materiales que permitan diferenciar los restos arqueológicos de las intervenciones posteriores.

\section{b) El patrimonio histórico}

Los edificios o monumentos de los siglos XVI hasta finales del siglo XIX forman parte del tejido urbano actual, y han pasado por un proceso de transformación, reutilización, y restauración. Las políticas de conservación del patrimonio histórico han evolucionado desde la intervención en inmuebles aislados hasta las propuestas de conservación de zonas de monumentos o centros históricos.

El inventario de los monumentos históricos se constituyó, en un principio, por edificios religiosos registrados entre 1929 y 1933. Los esfuerzos de catalogación se concentraron posteriormente en el INAH. Salvador Díaz-Berrio, en Patrimonio Histórico Inmueble, define dos períodos de actividad en el INAH en materia de conservación del patrimonio cultural histórico. Durante la primera etapa (1939-1960), se registró una actividad moderada de estudio de inmuebles históricos, y de publicaciones. Se ejecutó asimismo un volumen importante de obras de protección, liberación y consolidación de inmuebles, y se emitieron declaratorias individuales de monumentos. El Instituto era hasta ese momento un organismo académico y científico, situación que se modificó a partir de 1964 cuando adquirió también una función de órgano de servicio público federal. En la segunda etapa (de 1964 a la fecha), se iniciaron programas de posgrado en restauración de monumentos y se consolidó la actividad de catalogación del patrimonio cultural, y de publicación. A medida que aumentaron los proyectos de remodelación de espacios públicos en la ciudad de México, y que se incrementó la labor de revisión y autorización de obras e intervenciones en monumentos y zonas típicas, disminuyó el registro de nuevas declaratorias de monumentos. 
Con la promulgación de la Ley Federal sobre Monumentos y Zonas Arqueológicas, Artísticas e Históricas en 1972, el INAH incrementó sus contactos con organismos internacionales como el ICCROM, el ICOM, y el ICOMOS, e inició la publicación de textos especializados sobre restauración. Impulsó estudios para delimitar, proteger y rehabilitar las zonas de monumentos históricos, considerando su inserción en el acelerado proceso de urbanización del país como áreas con valores, características y funciones particulares que debían integrarse en los planes generales de desarrollo urbano. EI INAH disminuyó su participación directa en obras de restauración, las que fueron asumidas por dependencias de los gobiernos estatales y municipales, o por el gobierno federal.

La ley federal de 1972 estableció las zonas de monumentos históricos como una serie de elementos comprendidos en una cierta extensión territorial, y no como un conjunto de elementos, lo cual implicaba realizar un análisis individual de cada una de las construcciones incluidas en las zonas mencionadas. Se definieron las delimitaciones, los inventarios de bienes y sus declaratorias correspondientes, junto con una normatividad para este tipo de zonas. Actualmente existen 56 zonas de monumentos históricos en toda la República.

En Protección del patrimonio cultural urbano, Salvador Díaz-Berrio apunta que, en el marco de la Conferencia General de la UNESCO realizada en 1972, se adoptaron políticas para atribuir al patrimonio cultural y natural una función en la vida colectiva, e integrar la protección de ese patrimonio en los programas de planificación general, y en particular en los programas de desarrollo urbano. Un momento significativo para el desarrollo de esta labor en México ocurrió en 1974, con la impartición de un curso sobre conservación y restauración de centros urbanos y conjuntos históricos en la Universidad Nacional Autónoma de México, en el que se propuso tomar en consideración el análisis histórico de las estructuras urbanas, el análisis armónico-formal urbano, y el estudio del medio sociocultural de las poblaciones. Estos temas retoman los términos de consistencia física, polaridad histórica y polaridad estética, que define Césare Brandi. Se consideran entonces la arquitectura y las ciudades como parte de los bienes 
culturales, tomando en cuenta su valor de uso actual y futuro en un amplio contexto urbano y territorial. En el análisis global de las ciudades históricas se incluyeron a partir de ese momento los factores utilitarios y los factores socioeconómicos, además de los valores históricos y estéticos.

En Mexico el interés por la conservación de ciudades históricas comenzó a manifestarse desde 1930. Conviene destacar el proyecto realizado en Guanajuato por el Arq. Victor Manuel Villegas como un ejemplo de la transición de estudios de restauración de monumentos aislados hacia la intervención en conjuntos urbanos. En este caso específico se peatonalizó el centro de la ciudad, se entubó el río que lo cruza, y se restauraron inmuebles históricos. Sin embargo, conviene apuntar que, en contraposición con los principios adoptados oficialmente y en aras de lograr la revitalización socio-económica de ciertas ciudades, numerosos proyectos buscaron lograr el rescate de valores estéticos, a menudo a expensas de la veracidad histórica. Tal es el caso del centro histórico de Morelia, cuyos edificios fueron recubiertos de cantera por el Arq. Manuel González Galván a partir de 1950, o de los pueblos del Estado de México, cuyos inmuebles fueron encalados y pintados de blanco por el Arq. Francisco Artigas hacia 1960. Otros ejemplos de intervenciones de gran impacto se dieron en la década de los años 80 , cuando se derribaron varias manzanas de los centros históricos de las ciudades de Guadalajara y Monterrey para conformar unas plazas cívicas de enormes proporciones que modificaron irremediablemente la traza urbana original de estas ciudades.

En cuanto a las intervenciones en monumentos históricos, han coexistido diversas tendencias a lo largo del siglo pasado, desde las que pregonaron una intervención mínima, limitada a la conservación de los restos monumentales como documentos históricos, hasta aquellas que buscaron reconstituir el valor artístico del monumento, y por ende supusieron proyectos de reconstrucción o integración mediante elementos contemporáneos. Dos textos citados por Díaz-Berrio ilustran esta última postura:

La validez estética de una obra de arquitectura, persiste por encima de la permanencia de materia arqueológica (...) De esta consideración crucial surge la diferencia y la autonomía entre 
los dos tipos de autenticidad histórica de un monumento: la estética y la simplemente arqueológica: llegando a la afirmación de que una perfecta copia óptico-háptica de una obra, objetiva la validez histórico-estética de la creación de su autor por encima de la totalmente ausente autenticidad arqueológica. (JOSÉ VILLAGRÁN GARCÍA).

Una restauración no es el trabajo de embalsamamiento de un edificio por su valor históricoestético, sino continuar su vida con los elementos que todavía perduran injertándole otros elementos actuales, de tal manera que el monumento sea apto para continuar su vida arquitectónica. Una restauración debe aunar a un mismo tiempo un respeto total hacia todo aquello que haya sobrevivido, y complementarlo en todos aquellos elementos que hayan desaparecido, con un sentido actual, contemporáneo, moderno. (RICARDO DE ROBINA).

Un ejemplo de las intervenciones de Ricardo de Robina, durante los años 60, son las iglesias de San Lorenzo, Santiago Tlaltelolco y San Joaquín en la ciudad de México, donde, entre otras cosas, se eliminaron los aplanados para dejar visible la mampostería original, y se agregaron elementos litúrgicos contemporáneos, diseñados por artistas plásticos de reconocido prestigio. Otra variante son los proyectos que buscan rehabilitar monumentos históricos mediante la integración de elementos contemporáneos y su conversión a usos que implican adecuaciones mayores, como se puede advertir en numerosos proyectos realizados en el centro histórico de la ciudad de México en la década de 1990.

Sin embargo, la gran mayoría de las restauraciones se han apegado a los principios expuestos en la Carta de Venecia, consistiendo en obras de protección, consolidación, liberación, nivelación, y rescate de los elementos existentes. Muchos inmuebles han mantenido su uso original (en el caso, por ejemplo, de iglesias e inmuebles para habitación); otros se han adaptado a usos acordes con sus características espaciales, como museos, casas de cultura, escuelas y centros de estudio, archivos y bibliotecas, centros vacacionales, hoteles, comercios, oficinas públicas o privadas, y el uso predominante de la vivienda.

Hoy en día se fortalece una coordinación de labores entre los distintos organismos involucrados en la conservación del patrimonio, relacionada con una concepción más 
global del patrimonio cultural. Se fomenta la creación de comisiones consultivas estatales de monumentos históricos, y existe una colaboración creciente con organismos académicos, científicos, técnicos, sociales y civiles, tanto nacionales como extranjeros.

\section{c) El patrimonio artístico}

A nivel internacional, la preocupación por la conservación del patrimonio arquitectónico y urbano del siglo XX es un fenómeno relativamente nuevo. Se concretó hace casi 20 años con la creación de DOCOMOMO, y la inclusión de expresiones culturales recientes en la lista del patrimonio considerado por ICOMOS.

La realización de un inventario es fundamental para la protección del patrimonio artístico de México, cuya responsabilidad recae en el Instituto Nacional de Bellas Artes. El Instituto cuenta con un catálogo cuya consulta no es pública, y que no es suficiente para lograr la protección del patrimonio, ya que es necesario un Decreto Presidencial para que un bien sea declarado monumento artístico y goce de protección legal. Existen actualmente menos de 20 inmuebles o conjuntos que han sido declarados monumentos artísticos en el país, y la mayoría de ellos se encuentran en la ciudad de México.

Algunas dependencias de gobiernos estatales o municipales (como la Secretaría de Desarrollo Urbano en el caso de la ciudad de México) han elaborado catálogos del patrimonio del siglo $\mathrm{XX}$, y aplican normativas especiales para expedir permisos de obra. Sin embargo el patrimonio arquitectónico y urbano del siglo $X X$ es significativamente más vulnerable que los bienes de otros períodos de la historia del país.

\section{Bibliografía}

BECERRIL MORO, José Ernesto. El derecho del patrimonio histórico-artístico en México. México: Ed. Porrúa, 2003.

BERNAL, Ignacio. Historia de la arqueología en México. México: Porrúa, 1979. 
DIAZ-BERRIO FERNANDEZ, Salvador. Patrimonio Histórico Inmueble. En: OLIVE NEGRETE, Julio Cesar; COTTOM, Bolfy (Coords.). INAH: una historia. 3. ed. México: INAH, 2003. v. 1. Primera Parte, Cap. IV.

DIAZ-BERRIO FERNANDEZ, Salvador. Protección del patrimonio cultural urbano. México: INAH, 1986.

DIAZ-BERRIO FERNANDEZ, Salvador. Conservación y rehabilitación en zonas de monumentos. En: METODOLOGÍA del trabajo de conservación de conjuntos históricos, Escuela Nacional de Conservación, Restauración y Museografía. México: INAH, 1989. Cuaderno de trabajo \# 2,

MANGINO TAZZER, Alejandro. Retrospectiva histórica de la arquitectura mexicana, su restauración. México: UAM; UNAM, Facultad de Arquitectura, 1983.

MOLINA MONTES, Augusto. La restauración arquitectónica de edificios arqueológicos. México: INAH, Departamento de Restauración del Patrimonio Cultural, 1975.( Colección Científica n. 21).

CONSERVACIÓN del Patrimonio. Orientaciones de las Escuelas de Arquitectura en América Latina. Florencia: Red Alvar - Patrimonio y Proyecto; Alinea Editrice, 2006.

DECRETO de ley de salvaguarda del patrimonio urbanístico arquitectónico del Distrito Federal. Gaceta Oficial del Distrito Federal, 13 abr. 2000. Gobierno del Distrito Federal, México, 2000

LEY federal sobre monumentos y zonas arqueológicos, artísticos e históricos. Diario Oficial, 6 mayo 1972. México: Secretaría de Educación Pública; INAH, 1975.

\section{Recursos electrónicos}

Instituto Nacional de Antropología e Historia Icomos

www.inah.gob.mx/index_.html

Docomomo www.international.icomos.org

Conaculta www.docomomo.org www.conaculta.gob.mx

* Arquiteta. Especialização e Mestrado em preservação de monumentos e sítios históricos pela Katholieke Universiteit Leuven (Bélgica). Professora do Departamento de Arquitectura da Universidad Iberoamericana, Cidade do México.

e-mail: gabriela.lee@uia.mx 